\title{
Dynamics of the Beveridge Curve and Global Crises
}

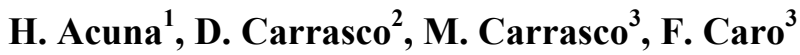 \\ ${ }^{1}$ Centro de Estudios Financieros, ESE Business School, Universidad de los Andes, Chile \\ ${ }^{2}$ Dirección de Estudios, Empresa Nacional del Petróleo, Chile \\ ${ }^{3}$ Facultad de Ciencias Económicas y Administrativas, Pontificia Universidad Católica de Chile, Chile
}

Copyright $\bigcirc 2018$ by authors, all rights reserved. Authors agree that this article remains permanently open access under the terms of the Creative Commons Attribution License 4.0 International License

\begin{abstract}
This research studies the relation between unemployment and vacancies for Chile between 1994I-2012IV with a special focus on the stages of global crises. Looking at the data, we observed that consequently to the Asian financial crisis, Chile showed an outward shift from the Beveridge Curve which indicates an efficiency loss in the matching process between labor supply and demand. On the other hand, the curve moved inwards as a result of the sub-prime crisis, a proof that supports an improvement in the matching process. We examine a series of factors previously used in the literature with the aim to decompose the changes in the unemployment rate and distinguish the factors that explained the changes in the efficiency of the matching process during both crises. The results, point out that the composition of the labor force and the real wage level were the main variables that explained the efficiency changes.
\end{abstract}

Keywords Beveridge Curve, Labor Market, Economic Crises, Matching Function, Efficiency Changes

JEL Classification E24, G01, J22, J23, J60, J64

\section{Introduction}

The Beveridge Curve has been widely used to describe the state of labor market and distinguish structural and cyclical changes. Blanchard and Diamond [5] argued that the usefulness of the Beveridge Curve had been understated by the macroeconomists. However, due to high and persistent levels of unemployment in Europe during the 80 's, the interest for studying this tool gave rise to new empirical studies in order to estimate the labor matching function (Blanchard and Diamond [5]; Bleakley and Fuhrer [6]; Petrongolo and Pissarides [24]). Similarly, several studies were developed with the aim of analysing the stability of the Beveridge Curve and the reasons for its changes (Borsch-Supan [10]; Wall and Zoega [29]; Valletta [28]).

The study of the Beveridge Curve and the evolution of the unemployment have acquired greater relevance during the times of crises. The evidence has indicated that in the initial stage of an economic downturn, the vacancies fall dramatically while the unemployment rate increases (Hobijn and Sahin [19]). Subsequently, in the recovery stage, the vacancies gradually return to an expansion path, but the unemployment level has tended to remain higher, which points out an outward shift from the Beveridge Curve. Thus, the changes in the curve became very interesting during crisis periods, because they could suggest the existence of structural changes in the unemployment-vacancies relation, and therefore, in the labor market as a whole.

Even though the important increase of unemployment caused by crisis episodes has been attributed to cyclical factors (Kugler [21]), the disparities between the labor supply and demand have become more relevant in comparison to the pre-crisis years. In particular, this kind of friction implies the existence of an unemployment level that is cyclical and contains an important structural component that could affect the short-term stabilization policies such as the monetary policy, which could trigger inflation combined with high levels of unemployment. As a consequence, the ability to discriminate if an increase in the unemployment rates is caused by cyclical factors as scarcity of labor demand or if it is caused by labor supply factors such as a disparity between the offered attributes and those which are required by employers is vital for the effectiveness of economic policies (Bonthuis et al. [7]).

Due to the last financial crisis, the interest for studying the Beveridge Curve dynamics to determine which factors influence its behavior has increased. However, literature has only focused on developed markets such as the United States (Hobijn and Sahin [19]) and the Euro area (Bonthuis et al. [8]; Sell and Reinisch [26]; Bonthuis et al. [7]). 


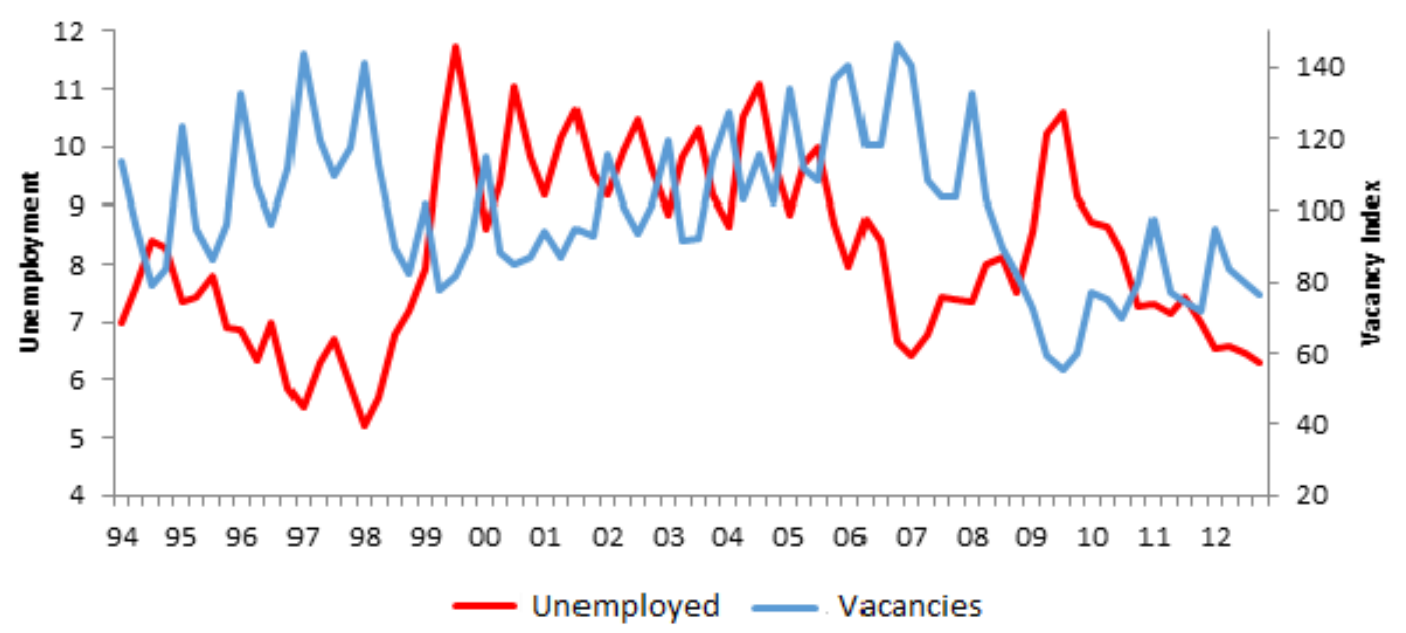

\section{Source: Central Bank of Chile}

Figure 1. Evolution of Unemployment and Vacancy Index between 1994 and 2012

Chile was not immune to the impact of the global crises in the deterioration of its labor market and in the Asian and the sub-prime crises unemployment and vacancy rate varied considerably (see Figure 1). Specifically, in both crises the unemployment reached levels over $10 \%$, whereas the vacancies dropped significantly. However, there were some differences. In the recovery stage after the Asian crisis, although vacancies showed an improvement, the unemployment kept higher than those levels that Chile showed in the years before this episode, which suggests a structural change in the labor market. On the other hand, in the aftermaths of the sub-prime crisis, the unemployment did not only reverse its upward trend in the end of 2009, but also kept decreasing in the following years, which could be a sign of an improvement in the labor matching.

This paper studies the Beveridge Curve of Chile from 1994 to 2012 putting a particular focus on the development of the curve between the crisis periods. Firstly, the periods of change in the Beveridge Curve are identified through visual inspection to know its magnitude and direction. Then, a model is constructed with the aim to measure the shifts of Beveridge Curve and identify the main factors that explain them. Finally, the econometric results support the visual inspection analysis and show that the young and female labor participation as well as the real wages had a significant incidence in the movements of the Beveridge Curve.

\section{Theoretical Framework}

Beveridge [4] identified the negative relation between unemployment and job vacancies. His goal was to determine how far the economy of the United Kingdom was from a full employment situation. Even though with its use was not possible to explain the full dynamics of the labor market, the Beveridge Curve was established as a tool to summarize the state of the labor market and explain the adjustment process to different shocks.

The starting point to derive the Beveridge Curve is the matching function. Based on Pissarides [24] this function determines the number of recruitments in a period of time given the number of workers that seek employment and the companies that require workforce. The intuition of the matching function is that increases in the number of employers seeking for workers or in the number of workers seeking for jobs should increase the amount of recruitments. However, the labor market presents various sources of heterogeneity, data imperfections and other frictions that could alter the number of recruitment, for example, when a vacancy is not filled due to unawareness of its existence or specific requirements of the company. Thus, in the stationary state the unemployment is produced because job relations finish before the unemployed seek for a new job.

\subsection{Beveridge Curve: Formal Model (Pissarides [24])}

Let $U$ and $V$ the number of unemployed and vacancies in the economy. Then, the number of recruitments $C$ will be the result of the matching function of $m: U x V \rightarrow \mathrm{R}^{+}$such that $C=M(u, v)$ where:

- $\frac{\partial m(U, V)}{\partial U}>0$ : higher the number of people searching for a job, higher the number of applications.

- $\frac{\partial m(U, V)}{\partial V}>0$ : if there are more offers, it would be easier to find vacancies to apply for.

Supposing constant returns to scale in $m$, the number of recruitments would vary in proportion to the number of vacancies and unemployed. Thus: $\frac{C}{L}=\frac{M(U, V)}{L} \rightarrow c=m(u, v)$, where $L$ represents the workforce. Assuming continuous time, let $\eta$ the probability of being fired which follows a 
Poisson process. Then, the dynamic of the unemployment rate is given by the following equation where unemployment rate increases if the dismissal rate is higher than the hiring rate.

$$
\dot{u}=\eta(1-u)-m(u, v)
$$

The steady state condition for unemployment rate corresponds to the Beveridge Curve and shows the long-term relation between the vacancy and unemployment rates. This relation depends on the probability of being fired $\eta$ and the recruitments rate $c$.

$$
u^{*}=\frac{1}{\eta}\left[\eta-m\left(u^{*}, v^{*}\right)\right]
$$

Differentiating the unemployment rate with respect to the vacancies, we obtain that the first derivative is negative while the second is positive. Thus, the Beveridge Curve has a negative trend and it is convex to its origin. The movements along the curve occur within the economic cycle. The vacancies usually follow the movement of the economic cycle, because in a boom period the companies tend to demand more workers while during a recession tend to reduce them. The opposite holds with unemployment, it decreases during the boom and increases during the recession. Instead, movements of the Beveridge Curve represent improvements or deteriorations in the matching function of the labor market caused by changes in the frictional unemployment due to structural factors. In particular, literature has determined that certain variables such as workforce composition, structural factors, long-term unemployment and reallocation of the employment between economic sectors are the main factors that produce movements in the Beveridge Curve (Bouvet [11]).

Thus, the position of the curve is a measure of the efficiency in the process of labor market adjustment: when the curve is more distant to its origin, for each level of unemployment there is a larger amount of vacancies so the reallocation of labor is less efficient. On the contrary, if the curve is closer to its origin, for each level of unemployment there is a lower amount of vacancies so the matching function is more effective.

The evidence related to the last financial crisis, has shown how negative shocks in aggregate demand has caused impairments in the matching function. Diamond and Sahin [15] using data of the United States between years 1950-2014 show that episodes of matching impairment coincide with episodes of economic recession. Moreover, the authors show that deterioration in the matching function could generate long-term unemployment because certain vacancies are not filled systematically.

\subsection{Empirical Framework}

During the sub-prime crisis, the exports became the main channel for negative shocks in the domestic labor markets. The international trade dropped $19.3 \%$ in the first quarter of
2009, adding pressure on the product and the employment, which started to show signs of recovery during the second half of 2009. Additionally, product exports dropped more than service exports but were less relevant on labor efficiency because decreases in services are directly related with job destruction (Borchert y Mattoo [9]).

Gamberoni et al. [16] show that, on average, the impact over the employment of a domestic debt crisis tends to be more than two times the impact of a global crisis. However, economic shocks could interact with domestic shocks and amplify the negative impact on the employment level because exporting firms are more sensitive to external financial conditions which tend to become more stringent in recession periods. In this respect, Barnichon and Figura [1] using data from different economic sectors in the United States, identify that the movements of the curve are caused by the diminution of recruitments in the export and construction sectors.

Among the structural factors which could produce movements of Beveridge Curve, real wage has been highly investigated. In particular, the impact of real wage on Beveridge Curve is ambiguous because it depends on the elasticity of labor supply and labor demand. From the perspective of labor supply, higher real wages tend to encourage unemployed to accept jobs easily. Instead, from the perspective of the labor demand, higher real wages tend to cause a reluctant disposition from the employer to recruit workers.

Mehrotra and Sergeyev [20] show that a productivity shock in some economic sectors followed by increases on wages trigger a redistribution of labor among sectors which produce an outward movement in the Beveridge Curve. De Francesco [14] estimates a Beveridge Curve for Australia adding real wage and long-term unemployment. The author concludes that increases in these variables enfeeble the adjustment in the labor market, causing an outward movement in the Beveridge Curve. Groenewold [17] uses cointegration techniques to model the long-term relation between unemployment and vacancies. Through an extended curve, where the real wage is the most significant variable, he obtained similar results to De Francesco [14]. Saglam and Gunalp [25] using a time-series analysis of unemployment, vacancies, real wage and labor productivity, find a cointegration relation that allows to conclude that the real wage has a positive and significant impact on the unemployment.

The composition of the workforce also could play an important role in the labor market. During crisis episodes, shocks have affected mainly male-dominated sectors whereas the public sector - where women have a larger representation level - has tended to suffer fewer drawbacks. In this regard, evidence shows that the labor matching function in economies with higher female participation are more protected against shocks because these economies have better capacities of keeping consumption shocks to the minimal. 
Bonthuis et al. [8], through an ARDL model, analyze the Beveridge Curve in the Euro-zone for the last 25 years, finding outward movements due to the sub-prime crisis. They conclude that higher labor participation in the construction sector and the difference of skills are important determinants in the deterioration of the matching. However, the authors also find that a high female participation in the workforce mitigate this effect. Similarly, Bonthuis et al. [7] indicate that countries with higher proportion of young people in their workforce are significantly less exposed to a deterioration of the matching function. In particular, even though young workers are more susceptible to economic crises, a younger workforce reduces the probability of a sectoral imbalance. This result supports the fact that younger workers who have lost their jobs tend to remain less time unemployed than an older ones (Barnichon and Figura [1]). Moreover, this result is supported by the fact that geographical and sectoral redistribution costs are lower among younger workers (Barnichon and Figura [1]).

Finally, Bova et al. [12] motivated by the high persistence of the unemployment level after the sub-prime crisis, explain which are the factors and policies that have caused movements of Beveridge Curve. Using data of 12 OECD countries between 2001 and 2013, they identify that an older workforce and a strict legislation of employment had a negative impact in the matching function. Conversely, more female participation in the labor market in conjunction with a younger workforce as well as higher level of education had a positive impact.

\section{Methodology and Data}

\subsection{Identification of Structural Changes}

Based on methodology used by Bonthuis et al. [8] and Bova et al. [12], we start with a visual inspection of the trajectory followed by the relation between the vacancies and unemployment. This analysis is complemented using the approach of Bellani et al. [3] which uses the following specification:

$$
\log \left(u_{t}\right)=\alpha+\beta_{1} \log \left(v_{t}\right)+\varepsilon_{t}
$$

where $u_{t}$ is the unemployment rate and $v_{t}$ is the vacancy rate in period $t$.

Then, the Beveridge Curve is estimated to analyze its behavior during the pre-crisis periods as well as during them. The application of SQUARED CUSUM test to this specification enables to detect the presence of possible structural changes that the relation of unemployment and vacancies could have. Subsequently, using the following specification, the model is extended adding cyclical and structural variables with the aim to determine which variables have had an impact in the Chilean Beveridge Curve during the economic crises:

$$
\begin{gathered}
\log \left(\mathrm{u}_{\mathrm{t}}\right)=\alpha+\beta_{1} \mathrm{v}_{\mathrm{t}}+\beta_{2} \mathrm{~W}_{\mathrm{t}}+\beta_{3} \text { expser }_{\mathrm{t}}+ \\
+\beta_{4} \text { fem }_{\mathrm{t}}+\beta_{5} \text { young }_{\mathrm{t}}+\beta_{6} \text { old }_{\mathrm{t}}+\beta_{7} \text { int }_{\mathrm{t}}+\varepsilon_{\mathrm{t}}
\end{gathered}
$$

where $w$ is real wage index, expser are the total exports over the GDP, fem is the female participation in the workforce, young is the participation of younger workers (under the age of 25 years old) in the workforce and old is the participation of older workers (55-64 years old) in the workforce. All variables are expressed as logarithm. Given the potential endogeneity of real wage and vacancies, least squares are applied in two stages. Real wage is expressed as a function of exchange terms and labor productivity. In the case of vacancies, the variable is expressed as a function of its lags.

A limitation of this specification is the possible underestimation of vacancy index developed by the Central Bank of Chile which is constructed using newspaper advertisements. Mujica [22] points out that the emergence of job portals on internet could bias this vacancy index at the end of 2002. In consequence, we add the dummy variable int which takes the value 1 from 2002 and 0 in the previous years.

The tests of endogeneity in the regression of two stages enable the evaluation of the capacity of the instrumental variables to provide consistent estimators. Therefore, once the consistent estimator of unemployment is obtained in two stages, it is possible to make an approximation of the percentage variation of unemployment with $\Delta \ln (u) \approx$ $\Delta u / u$ and find the contribution that each of the explanatory variables had in the evolution of unemployment.

\subsection{Data}

The estimation is performed using quarterly data between 1994 and 2012 due its availability but also in order to avoid possible bias in the estimation because the vacancy index had a considerable drop after 2012 which is attributed to the massive appearance of internet job portals.

We used data of unemployment elaborated by the Instituto Nacional de Estadísticas (INE). The vacancy index is elaborated by the Central Bank of Chile. The real wage index elaborated by the INE since 1993 is used as an approach of real wages. The data related to female, younger and older participation over the workforce is provided by the ILO (International Labor Organization). The total exports over the GDP are obtained from the data base of the World Bank. Regarding the instrumental variables, we defined average labor productivity as the total product over the employment which was constructed using the data from INE and the World Bank. The exchange terms of Chile are available in the data base of the Central Bank of Chile.

Some data was only available in an annual frequency; in those cases we use the Denton procedure. This process produces a quarterly distribution of an annual variable using another quarterly variable as a benchmark. Specifically, for variables related to the composition of the workforce, the unemployment is used as a benchmark. 


\section{Empirical Analysis}

\subsection{Visual Analysis}

As Bova et al. [12], in figures 2 and 3 we present the evolution of the relation between unemployment and vacancies in the pre and post periods of both crises. In the first one, we can appreciate that for the period prior to the Asian crisis; the curve was steady with movements along itself which are attributed to cyclical factors. In the second quarter of 1999, when the Asian crisis was reaching its peak in Chile, the vacancies started to diminish and the unemployment rose strongly. Conversely, after the Asian crisis, the vacancies showed an improvement but the unemployment did not decrease which suggests an outward shift of the Beveridge Curve. This pattern continued until the end of 2006 when an important increase in the vacancies was produced, followed by a drop in the unemployment which stayed below $8 \%$.

Prior to the sub-prime crisis, vacancies contracted in a strong way (2007I-2007II) and the unemployment started to increase. However on the recovery process, the increase in vacancies was followed by a drop in the unemployment which could be a sign of an improvement in the matching function.

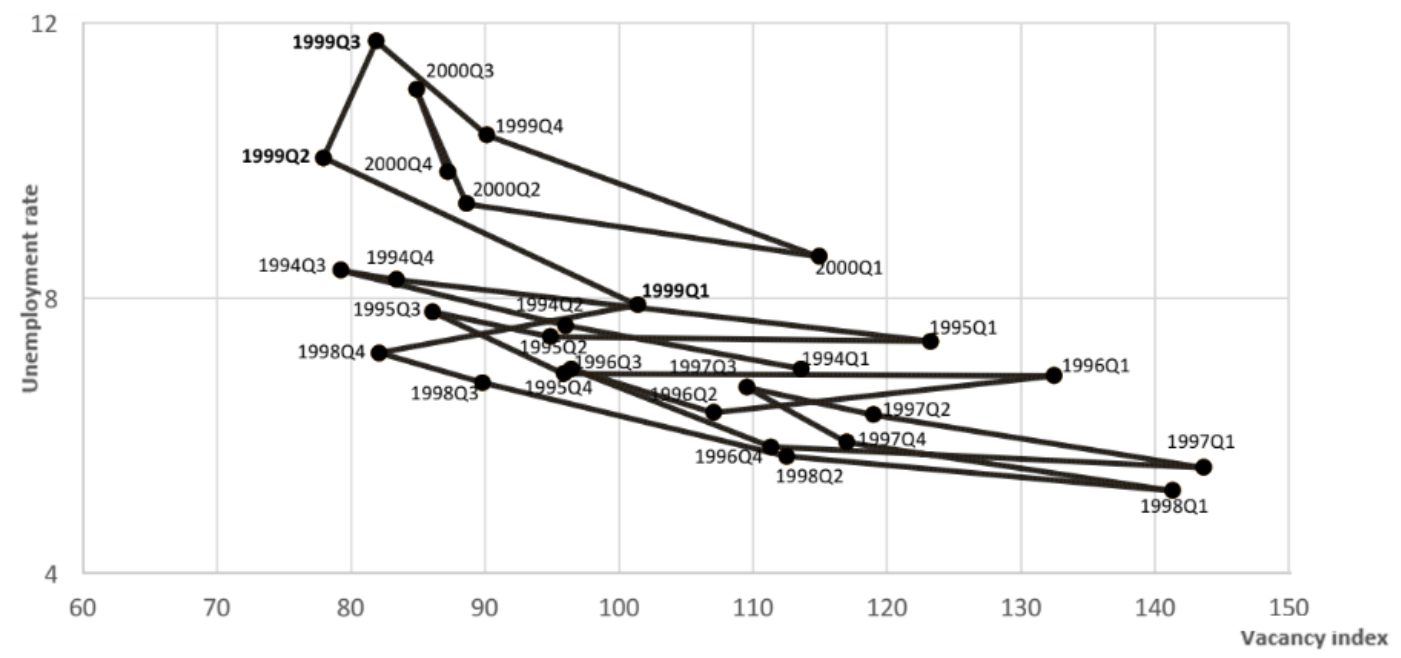

Source: Own elaboration with data from Central Bank of Chile

Figure 2. Beveridge Curve Evolution 1994I-2001IV

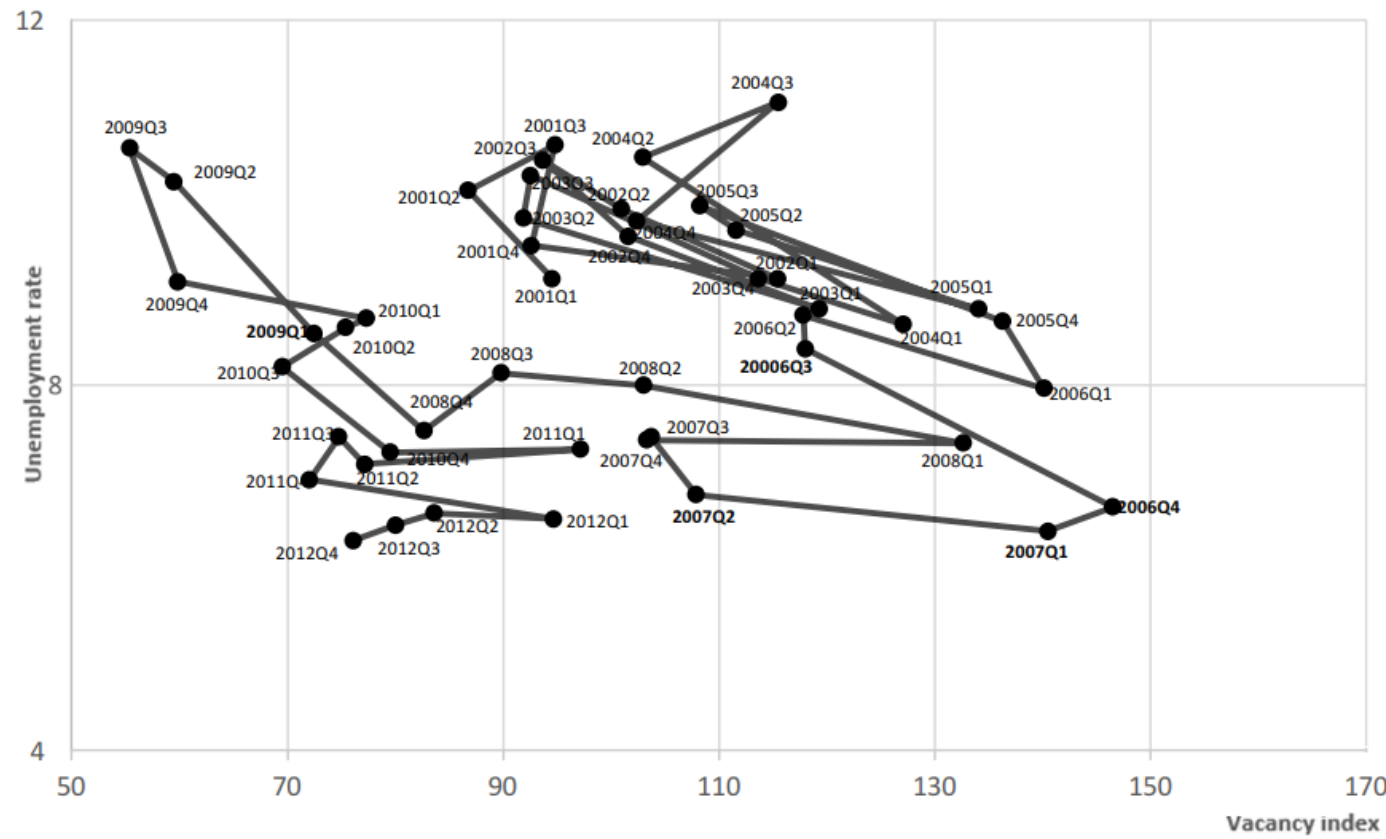

Source: Own elaboration with data from Central Bank of Chile

Figure 3. Beveridge Curve Evolution 2001I-2012IV 


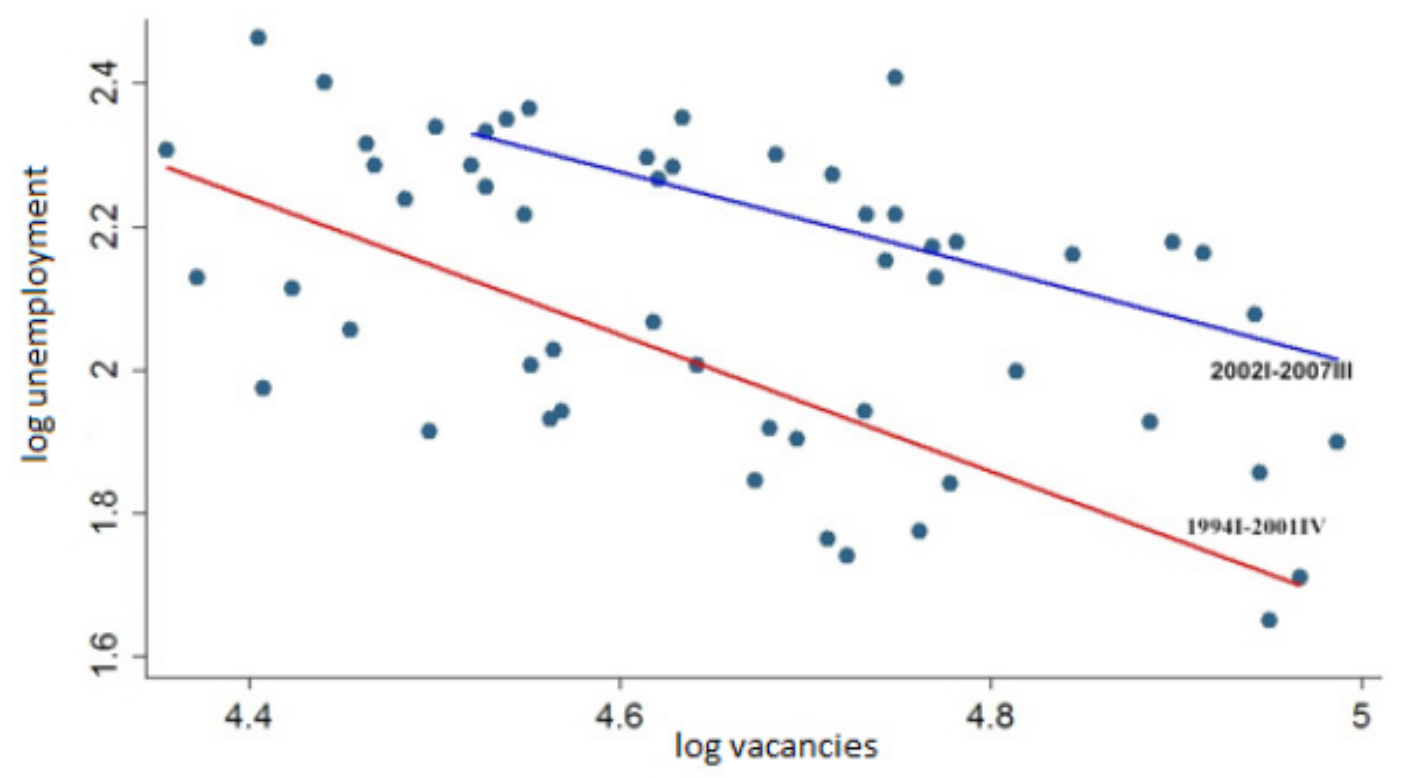

Source: Own elaboration with data from Central Bank of Chile

Figure 4. Beveridge Curve 1994I-2001IV; 2002I-2007III

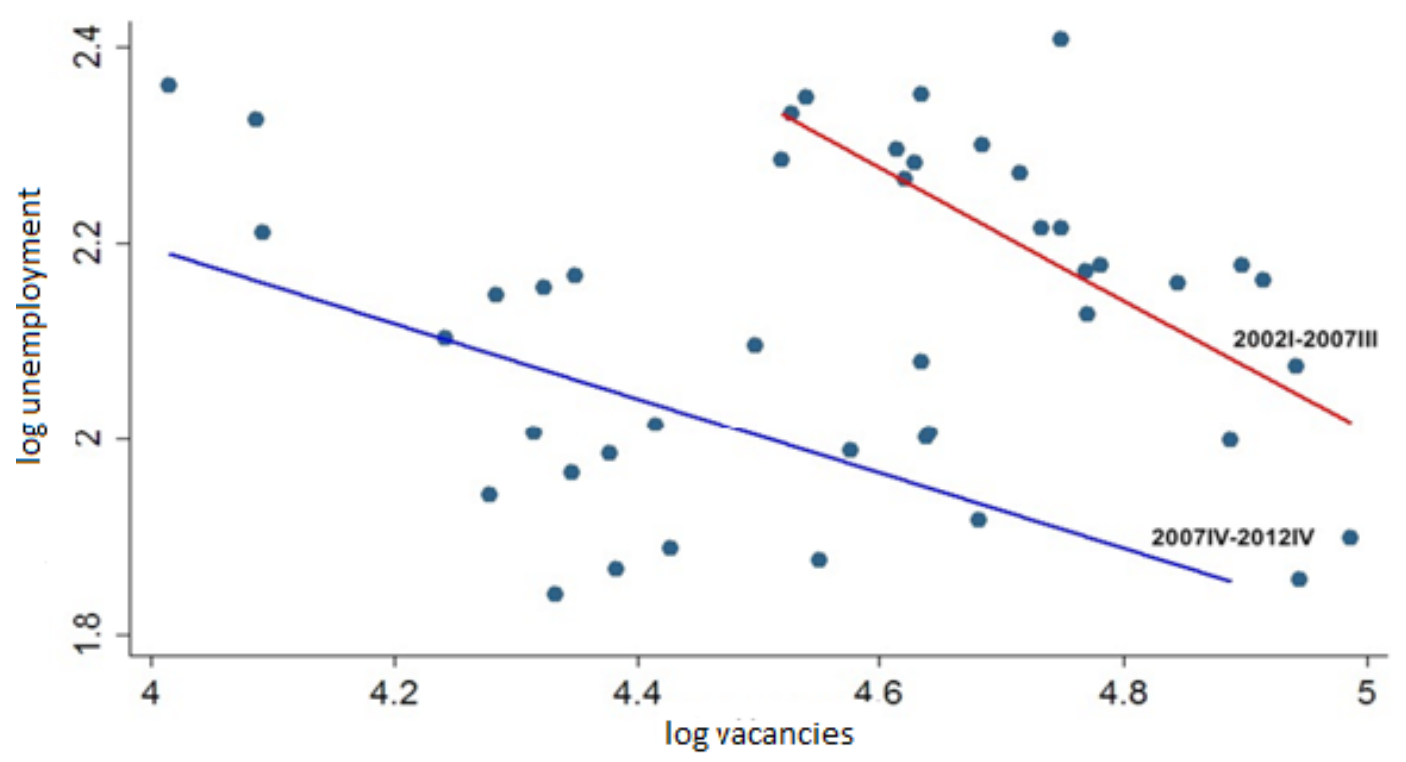

Source: Own elaboration with data from Central Bank of Chile

Figure 5. Beveridge Curve 2002I-2007III; 2007IV-2012IV

The previous analysis is supported with the estimation of the Beveridge Curve defined by Bellani et al. [3]. In figures 4 and 5 we present the estimation for periods 1994I-2001IV, 2002I-2007III, 2002I-2007III and 2007IV-2012IV. Additionally, the analysis to evaluate the presence of structural change throughout the SQUARED CUSUM stability suggests the presence of structural changes during the crisis periods which is also verified using the Chow test. More details are in annexes 1 and 2. These preliminary results support the main hypothesis of this research, which suggests that during the period of the Asian crisis the labor market efficiency weakened whereas improved during the sub-prime crisis.

\subsection{Extended Beveridge Curve}

Beveridge Curve is extended adding real wage index $(w)$, total exports over the GDP (expser), female participation in the workforce $(f e m)$, younger participation in the workforce rate (young), older participation in the workforce (old) and a dummy variable (int) that takes the value of 1 from 2002. Given the potential endogeneity of 
real wage and vacancies, instrumental variables are used to apply least squares in two stages using the following specification:

$$
\begin{gathered}
\log \left(\mathrm{u}_{\mathrm{t}}\right)=\alpha+\beta_{1} \hat{\vartheta}_{t}+\beta_{2} \hat{\mathcal{W}}_{t}+\beta_{3} \text { expser }_{\mathrm{t}}+\beta_{4} \text { fem }_{\mathrm{t}}+ \\
+\beta_{5} \text { young }_{\mathrm{t}}+\beta_{6} \text { old }_{\mathrm{t}}+\beta_{7} \text { int }_{\mathrm{t}}+\varepsilon_{\mathrm{t}}
\end{gathered}
$$

Due to high correlation with real wage, labor productivity and exchange terms were selected as instruments. Even though it is a necessary condition that the instrument is correlated with the endogenous variable, it is not sufficient to establish that the selected instruments have corrected the endogeneity. Thus, in order to validate the selection of these instrumental variables, tests are applied to check endogeneity (Wu [30]; Hausman [18]) and measure the quality of the instruments (Stock and Yogo [27]). See annexes 5 and 6.

With the purpose of analyzing preliminary results from the coefficient of the variables, Table 1 presents the results of the regression using ordinaries least squares. Table 2 shows the results using least squares in two-stages. In this regard, vacancies have negative and significant effect in unemployment, which is near to $-0.5 \%$. Prior to analyze the effect of the real wage, it is necessary to consider the forces that determine its effect. In particular, the effect of the real wage depends on the negotiation power of the employer and the employee, as well as the drive that moves the salaries which can be synthesized with the elasticity of the labor supply and demand. Inasmuch as the elasticity of the labor offer is relatively high, higher wage would tend to cause a negative impact on unemployment. On the contrary, if the elasticity of the labor demand is relatively high, higher wage would tend to cause a positive impact on unemployment. Therefore, our results support the existence of an elasticity of labor supply higher than the elasticity of labor demand. In particular, the estimated marginal effect of real wage on unemployment is equal to $-3.03 \%$ which is in accordance with the findings of De Francesco [14].

\begin{tabular}{|c|c|c|c|c|c|c|}
\hline Variable & (1) & (2) & (3) & (4) & (5) & (6) \\
\hline $\bar{V}$ & $\begin{array}{c}-0.356^{* * * *} \\
(0.105)\end{array}$ & $\begin{array}{c}-0.648^{* * *} \\
(0.085)\end{array}$ & $\begin{array}{c}-0.608^{* * *} * \\
(1.389)\end{array}$ & $\begin{array}{c}-0.551^{* * *} \\
(0.072)\end{array}$ & $\begin{array}{c}-0.524^{* * *} \\
(0.075)\end{array}$ & $\begin{array}{c}-0.583^{* * *} \\
(0.081)\end{array}$ \\
\hline$W$ & $\begin{array}{l}-0.319 \\
(0.341)\end{array}$ & $\begin{array}{c}2.255^{* * * *} \\
(0.411)\end{array}$ & $\begin{array}{c}-0.622^{\text {*** }} \\
(0.213)\end{array}$ & $\begin{array}{c}-2.512^{* * *} \\
(0.913)\end{array}$ & $\begin{array}{l}-1.861^{*} \\
(1.032)\end{array}$ & $\begin{array}{l}-1.641 \\
(1.003)\end{array}$ \\
\hline Expser & & & & & & $\begin{array}{l}0.450^{*} \\
(0.237)\end{array}$ \\
\hline Fem & & $\begin{array}{c}-5.542^{* * *} \\
(0.706)\end{array}$ & & $\begin{array}{c}3.708^{* *} \\
(1.743)\end{array}$ & $\begin{array}{c}3.506^{* *} \\
(1.740)\end{array}$ & $\begin{array}{c}2.241 \\
(1.821)\end{array}$ \\
\hline Young & & & $\begin{array}{c}-1.784^{* * *} \\
(0.169)\end{array}$ & $\begin{array}{c}-2.769^{* * *} \\
(0.491)\end{array}$ & $\begin{array}{c}-1.913^{* *} \\
(0.810)\end{array}$ & $\begin{array}{c}-1.840^{* * *} \\
(0.771)\end{array}$ \\
\hline Old & & & & & $\begin{array}{c}0.593 \\
(0.448)\end{array}$ & $\begin{array}{l}-0.323 \\
(0.482)\end{array}$ \\
\hline Int & $\begin{array}{c}0.107 \\
(0.074)\end{array}$ & $\begin{array}{c}0.318^{* * * *} \\
(0.060)\end{array}$ & $\begin{array}{l}0.078^{*} \\
(0.046)\end{array}$ & $\begin{array}{l}-0.079 \\
(0.086)\end{array}$ & $\begin{array}{l}-0.061 \\
(0.087)\end{array}$ & $\begin{array}{l}-0.110 \\
(0.090)\end{array}$ \\
\hline Constant & $\begin{array}{c}5.137^{* * * *} \\
(1.776)\end{array}$ & $\begin{array}{c}14.319^{\text {**** }} \\
(1.746)\end{array}$ & $\begin{array}{c}14.026^{* * *} \\
(1.389)\end{array}$ & $\begin{array}{c}12.787^{\text {**** }} \\
(1.474)\end{array}$ & $\begin{array}{c}9.011^{* * * *} \\
(3.207)\end{array}$ & $\begin{array}{c}10.203^{\text {**** }} \text { * } \\
(3.256)\end{array}$ \\
\hline$R^{2}$ & 0.165 & 0.562 & 0.682 & 0.703 & 0.710 & 0.732 \\
\hline Adjusted $R^{2}$ & 0.129 & 0.536 & 0.664 & 0.680 & 0.684 & 0.704 \\
\hline Observations & 76 & 76 & 76 & 76 & 76 & 76 \\
\hline
\end{tabular}

Table 1. Ordinary Least Squares (OLS)

Note: ${ }^{* *}: p-$ value $<0.01 ;{ }^{* *}: p-$ value $<0.05 ;{ }^{*}: p-$ value $<0.1$

Standard errors in parentheses 
Table 2. Least Squares in two-stages

\begin{tabular}{|c|c|c|c|c|c|c|}
\hline Variable & (1) & (2) & (3) & (4) & (5) & (6) \\
\hline$\hat{v}$ & $\begin{array}{c}-0.320^{* *} \\
(0.152)\end{array}$ & $\begin{array}{c}-0.862^{* * *} \\
(0.165)\end{array}$ & $\begin{array}{c}-0.757^{* * *} \\
(0.112)\end{array}$ & $\begin{array}{c}-0.538^{* * *} * \\
(0.131)\end{array}$ & $\begin{array}{c}-0.425^{\text {**** }} \\
(0.124)\end{array}$ & $\begin{array}{c}-0.519 * * * \\
(0.117)\end{array}$ \\
\hline$\hat{w}$ & $\begin{array}{l}-0.216 \\
(0.419)\end{array}$ & $\begin{array}{c}-1.765^{* *} \\
(0.520)\end{array}$ & $\begin{array}{c}-0.730^{* *} \\
(0.285)\end{array}$ & $\begin{array}{c}-2.597^{* * *} \\
(0.710)\end{array}$ & $\begin{array}{c}-2.680^{* * * *} \\
(0.651)\end{array}$ & $\begin{array}{c}-3.033^{* * *} * \\
(0.590)\end{array}$ \\
\hline Expser & & & & & & $\begin{array}{c}0.621^{* *} \\
(0.239)\end{array}$ \\
\hline Fem & & $\begin{array}{c}-4.082^{\text {*** }} \\
(0.779)\end{array}$ & & $\begin{array}{c}3.310^{* *} \\
(1.164)\end{array}$ & $\begin{array}{c}5.811^{* * *} \\
(1.263)\end{array}$ & $\begin{array}{c}4.875^{* * *} \\
(1.126)\end{array}$ \\
\hline Young & & & $\begin{array}{c}-1.89^{* * * *} \\
(0.225)\end{array}$ & $\begin{array}{c}-2.849^{* * *} \\
(0.388)\end{array}$ & $\begin{array}{c}-1.484^{* * * *} \\
(0.513)\end{array}$ & $\begin{array}{c}-2.096^{* * * *} \\
(0.532)\end{array}$ \\
\hline Old & & & & & $\begin{array}{c}1.486 \\
(0.403)\end{array}$ & $\begin{array}{l}-0.725 \\
(0.441)\end{array}$ \\
\hline Int & $\begin{array}{c}0.081 \\
(0.087)\end{array}$ & $\begin{array}{c}0.207 * * \\
(0.078)\end{array}$ & $\begin{array}{c}0.085 \\
(0.058)\end{array}$ & $\begin{array}{l}-0.014 \\
(0.065)\end{array}$ & $\begin{array}{l}-0.116^{*} \\
(0.0542)\end{array}$ & $\begin{array}{c}-0.183^{* *} \\
(0.073)\end{array}$ \\
\hline Constant & $\begin{array}{c}4.511^{* *} \\
(2.139)\end{array}$ & $\begin{array}{c}12.401 * * * \\
(2.360)\end{array}$ & $\begin{array}{c}15.588^{* * *} \\
(1.862)\end{array}$ & $\begin{array}{c}14.780^{* * * *} \\
(1.794)\end{array}$ & $\begin{array}{c}5.062^{* * *} \\
(3.104)\end{array}$ & $\begin{array}{c}8.366^{* * *} \\
(3.122)\end{array}$ \\
\hline$R^{2}$ & 0.080 & 0.347 & 0.596 & 0.640 & 0.690 & 0.742 \\
\hline Adjusted $R^{2}$ & 0.040 & 0.308 & 0.572 & 0.613 & 0.667 & 0.713 \\
\hline Observations & 75 & 75 & 75 & 75 & 75 & 75 \\
\hline
\end{tabular}

Note: ${ }^{* * *}: p-$ value $<0.01 ; * *: p-$ value $<0.05 ; *: p-$ value $<0.1$

Standard errors in parentheses

The coefficient of exports has a significant and positive value of $0.621 \%$. The literature supports a negative value for this variable in those economies whose export sector is considerable and labor intensive because a raise in the participation of exports over the GDP generates a drop on unemployment. Nonetheless, for an economy as Chile, with a large export sector and capital intensive, a raise in the participation of exports leads to a raise in the unemployment due to a higher participation of the capital in that sector.

Regarding the workforce composition, the younger workers participation is significant and negative in all the regressions, with a magnitude of $-2.096 \%$ in the last column. This goes in line with the research of Bonthuis etal. [8] which concluded that countries with higherproportion of youngerworkers are less prone to suffer an outward shift of the Beveridge Curve because this group tends to have more facilities to search work in periods of economic recovery after a crisis episode. On the other hand, older workers participation is non-significant in our regressions.
The parameter of female participation over the workforce has a negative and significant magnitude when the regression does not include the younger workers participation. If we suppose that during a crisis the most affected sectors are the ones dominated by men, with more female presence in the labor market, these effects can be amortized through the consumption channel of families. When younger workers participation is considered, the female participation parameter changes its sign due the bias of omitted variables caused in the regression of column (2). In particular, given that the correlation between both variables is positive and equals 0.41, the abbreviated regression (without younger workers participation), skews the parameter downwards. On the contrary, when this variable is included, this bias of the omitted variable is eliminated, increasing the value of the parameter to a positive one. The same occurs with the estimation of the younger workers effect without considering female participation, the parameter is skewed upwards, dropping 
from $-1.89 \%$ to $-2.089 \%$. Therefore, to interpret the parameter of female participation, it is necessary to consider the downward bias in the column (2). Thus, an increase of female workforce composition makes the unemployment increase, which could be in accordance with the assumption that the most affected sectors during a crisis are the ones with more female presence.

\subsubsection{Decomposition of Changes on Unemployment}

The first row of the Table 3 reports the average of quarterly $\Delta \ln (u)$ during pre and post crisis periods. Given that this variable reflects the proportional change, the first row refers to the average of quarterly variation of unemployment. Second row represents the average change predicted by the model. In row 3 we observe the quality of model predictions which matches significantly with the effective values for all periods except during 2000(I)-2003(IV) but in that period the dummy variable started to be implemented.

The six following rows represent the predicted effect on the unemployment caused by the behavior of the different variables for each period of time. For the construction of each one of these rows, we calculate the quarterly average of the variation of the different variables for each period of time and we weighted them by their estimators. The last row represents the variation of the unemployment explained by the model without considering the estimated effect of vacancies. Thus, this row can be interpreted as an approximation of Beveridge Curve movement during the different periods.

Observing Table 3, it is possible to notice that during the Asian crisis (1997-1999) the quarterly variation of vacancies - which had an average growth rate of $-5.2 \%$ boosted the unemployment by 2.7 percentage points (pp). Considering the marginal impact caused by the rest of the other variables, the joint effect on the unemployment rate was $2.4 \mathrm{pp}$. Therefore, during this period, although there was a movement along the Beveridge Curve which was caused by the movement of vacancies, also there was an outward movement. Specifically, the drop exhibited by the younger workers participation in the labor market that boosted unemployment in $1.7 \mathrm{pp}$, was particularly relevant to explain this movement.

During 2004 and 2006, the growth rate of vacancies was $1.25 \%$ which impacted the unemployment growth rate on $-0.65 \mathrm{pp}$. Regarding the rest of the variables, the joint effect attributed by the model was $-2 \mathrm{pp}$, which suggests an inward shift of the Beveridge Curve. The behavior of the salaries was particularly significant; whose expansion of $0.91 \%$ had an impact of $-2.76 \mathrm{pp}$ on the unemployment growth.

During the period of the sub-prime crisis (2007-2009) the unemployment increased significantly in $3.37 \mathrm{pp}$ which was partially explained by the drop of vacancies of $6.5 \%$. Considering the rest of the variables, the net effect of the vacancies was negative and equal to $-0.62 \%$, which is attributable to an inward shift of Beveridge Curve. In this regard, the behavior of the younger workers participation was relevant and presented an average growth rate of $1.09 \%$ that discouraged the unemployment growth by $-2.29 \mathrm{pp}$.

After the sub-prime crisis, vacancies increased on average $0.76 \%$ which, according to the model, decreased the unemployment growth by $0.4 \mathrm{pp}$. considering the other variables, their joint effect on the unemployment was $-2.65 \mathrm{pp}$ which is attributed to an inward movement of Beveridge Curve. According to the estimation, this shift is mostly due to the behavior of salaries. Specifically, the salary growth was $1.06 \%$ and discouraged the unemployment growth by $-3.23 \mathrm{pp}$.

Table 3. Breakdown of $\Delta(u)-2$ SLS

\begin{tabular}{|c|c|c|c|c|c|}
\hline Variable & "1997(I)/1999(IV) & "2000(I)/2003(IV) & "2004(I)/2006(IV) & "2007(I)/2009(IV) & "2010(I)/2012(IV) \\
\hline$\Delta \ln (u)$ & $5.71 \%$ & $0.43 \%$ & $-2.39 \%$ & $3.23 \%$ & $-2.97 \%$ \\
\hline$\widehat{\Delta \ln (u)}$ & $5.10 \%$ & $2.48 \%$ & $-2.65 \%$ & $2.75 \%$ & $-3.04 \%$ \\
\hline$\Delta \ln (u)-\widehat{\Delta \ln (u)}$ & $0.61 \%$ & $-2.05 \%$ & $0.27 \%$ & $0.48 \%$ & $0.08 \%$ \\
\hline Expser & $0.46 \%$ & $0.95 \%$ & $0.78 \%$ & $-0.83 \%$ & $-0.84 \%$ \\
\hline $\mathrm{Fem}$ & $0.74 \%$ & $1.38 \%$ & $1.54 \%$ & $3.39 \%$ & $1.52 \%$ \\
\hline Old & $0.55 \%$ & $0.07 \%$ & $-0.78 \%$ & $-1.16 \%$ & $-0.83 \%$ \\
\hline$W$ & $-1.08 \%$ & $-1.18 \%$ & $-2.76 \%$ & $0.27 \%$ & $-3.23 \%$ \\
\hline V & $2.70 \%$ & $0.27 \%$ & $-0.65 \%$ & $3.37 \%$ & $-0.40 \%$ \\
\hline Young & $1.73 \%$ & $0.99 \%$ & $-0.78 \%$ & $-2.29 \%$ & $0.74 \%$ \\
\hline $\begin{array}{l}\text { Net effect of } \\
\text { vacancies }\end{array}$ & $2.40 \%$ & $2.21 \%$ & $-2.00 \%$ & $-0.62 \%$ & $-2.65 \%$ \\
\hline
\end{tabular}


An important fact which is worth highlighting is that unemployment was mostly driven by a drop of the younger workers participation during the Asian crisis, while it was the main factor that discouraged it during the sub-prime crisis. Thus, a possible conclusion is the importance of promoting younger worker participation in the labor market during the crisis periods that are similar to the ones shown in this research.

In summary, the evidence supports that during the Asian crisis, the market lost efficiency while during the sub-prime crisis increased it. Even though we presented the main variables that have explained the movements of the Beveridge Curve we do not determine the channels of transmission. Therefore, it is precise to highlight the contexts in which both crises unfolded. In this regard, a relevant factor is the fact that during the sub-prime crisis the Internet was already in use as a frequent way of job seeking, which was captured by the model using the dummy variable whose estimator shows that the unemployment was affected negatively by this fact.

It is documented, that in periods of high unemployment, expansive monetary policies decrease unemployment through the reduction of the financial restrictions on the labor markets (Benito [2]). Thus, under a scenario of high unemployment the application of expansive policies could improve the matching function, which constitutes a possible source of efficiency gain. In this regard, the monetary policy that the Central Bank of Chile applied during the Asian crisis increased the nominal interest rate from $9 \%$ to $19 \%$ but in the case of the sub-prime crisis, the Central Bank of Chile had a proactive reaction and the interest rate reached minimum levels that promoted consumption, investment and employment. Moreover, during the sub-prime crisis, non-conventional monetary policy was applied in order to guarantee that the interest rate would keep low during a long time as well as the liquidity of financial system would improve.

Regarding the fiscal policy, this was expansive for both crises, but significantly more during the sub-prime crisis (Corbo and Schmidt-Hebbel [13]) when the Government of Chile compromised resources for US\$4.000 million equivalent to $2.8 \%$ of the GDP.

\section{Conclusions}

In Chile the consequences on the labor market caused by the global crises have been different due to the conditions that were presented and the policies implemented by authorities. During the recovery period of the Asian and the sub-prime crises there was a big difference on the unemployment trajectory. After the Asian crisis, the unemployment kept high while after thesub-prime crisis this variable decreased quickly.
To assess the performance of an economy during crises it is necessary to distinguish the unemployment generated by cyclical and the one generated by structural factors. When unemployment is cyclical and it is caused by the lack of jobs, the recovery on the economy will tend to decrease the unemployment. On the other side, if there is a structural imbalance between vacancies and labor supply, it is unlikely that the economic recovery will decrease unemployment.

Under this premise, this paper shows that Beveridge Curve for Chile presented a significant outward shift due to the Asian crisis indicating a marked imbalance on the labor market. On the contrary, there was an inward shift of the curve during the sub-prime crisis. Then, more variables were added in order to isolate the structural variables that could produce these movements.

The results suggest that the workforce composition and the level of wages were the main factors that explain the difference of unemployment trajectory between the crises. With the aim to detect the channel of transmission that could explain these movements, a variable was used from 2002 in order to control the use of internet as a platform for job seekers and isolate the effect of improvements of technology on the matching functions. The results detected this factor as a possible source to explain differences in the labor market efficiency between the crises.

\section{Acknowledgements}

We express our sincere thanks to Professor Francisco Rosende (RIP) who helped us with this paper.

\section{Annexes}

\section{Annex 1: Visual Analysis Regression}

Dependent Variable: log (unemployment) Method: MCO (Gauss-Newton / Marquardt steps) Sample: 1994.I-2001.IV

Observations: 32

Table 4. 1994.I-2001.IV

\begin{tabular}{lcccc}
\hline \hline & Coefficient & Standard Error & Statistical-t & Prob \\
\hline C & 4.453 & 0.757 & 8.520 & 0.000 \\
$\log$ (vacancies) & -0.957 & 0.164 & -5.818 & 0.000 \\
\hline$R^{2}$ & 0.530 & & & \\
Adjusted $R^{2}$ & 0.514 & & & \\
Statistical F & 33.853 & & & \\
Prob (Statistical F) & 0.000 & & & \\
\hline \hline
\end{tabular}


Dependent Variable: log (unemployment)

Method: MCO (Gauss-Newton / Marquardt steps)

Sample: 2002.I-2007.III

Observations: 23

Table 5. 2002.I-2007.III

\begin{tabular}{lcccc}
\hline \hline & Coefficient & Standard Error & Statistical-t & Prob \\
\hline $\mathrm{C}$ & 5.377 & 0.886 & 6.062 & 0.000 \\
$\log$ (vacancies) & -0.673 & 0.187 & -3.598 & 0.000 \\
\hline$R^{2}$ & 0.381 & & & \\
Adjusted $R^{2}$ & 0.351 & & & \\
Statistical F & 12.949 & & & \\
Prob (Statistical F) & 0.001 & & & \\
\hline
\end{tabular}

Dependent Variable: log (unemployment) Method: MCO (Gauss-Newton / Marquardt steps) Sample: 2007.IV-2012.IV

Observations: 21

Table 6. 2007.IV-2012.IV

\begin{tabular}{lcccc}
\hline \hline & Coefficient & Standard Error & Statistical-t & Prob \\
\hline $\mathrm{C}$ & 3.733 & 0.591 & 6.307 & 0.000 \\
$\log$ (vacancies) & -0.384 & 0.134 & -2.849 & 0.010 \\
\hline$R^{2}$ & 0.299 & & & \\
Adjusted $R^{2}$ & 0.262 & & & \\
Statistical F & 8.119 & & & \\
Prob (Statistical F) & 0.010 & & & \\
\end{tabular}

Annex 2: Squared CUSUM

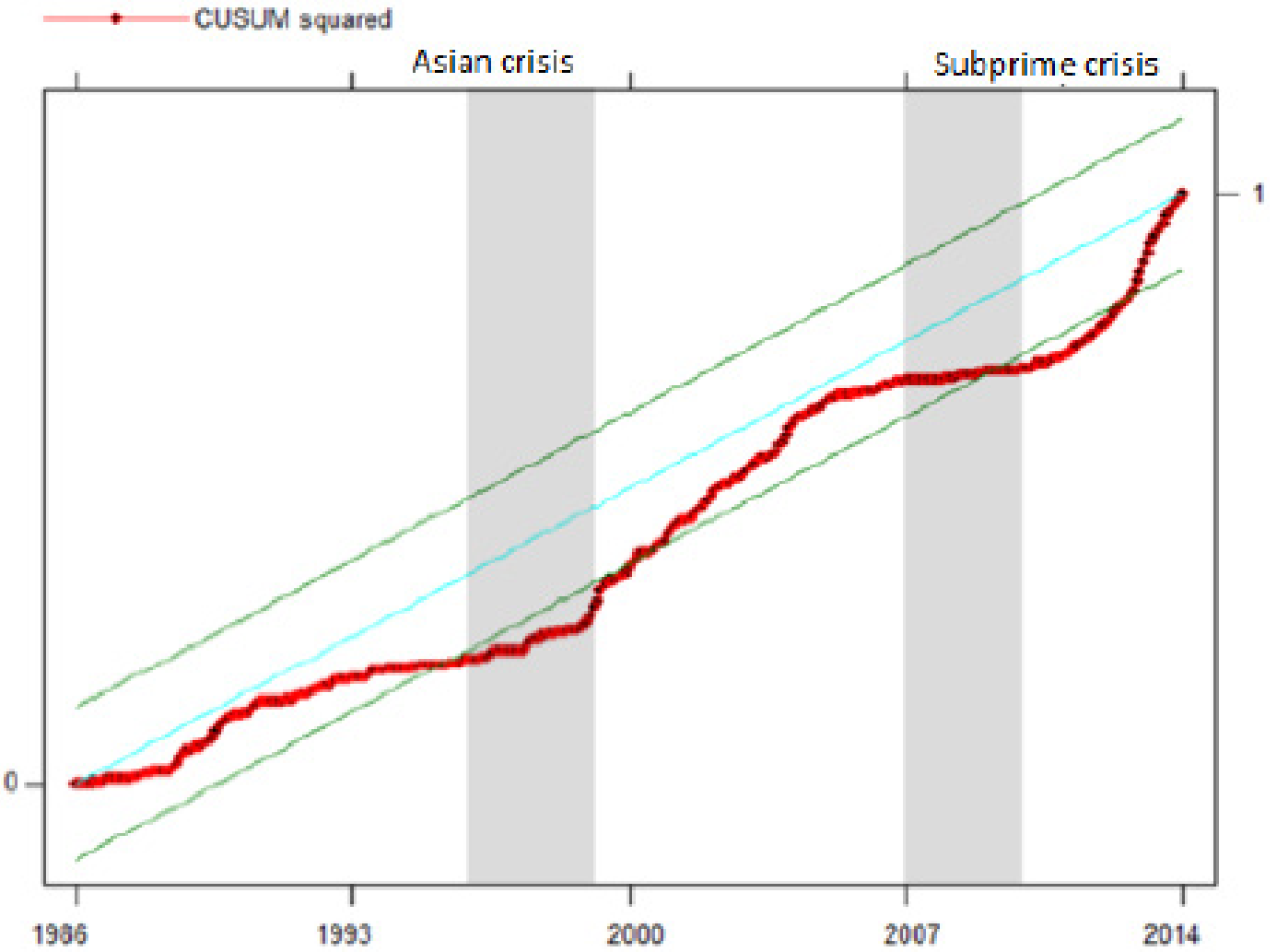

Figure 6. Squared CUSUM 
Table 7. Chow test

\begin{tabular}{lccc}
\hline \hline Analysis & F value & d.f.1 & d.f.2 \\
\hline First structural break & $5.715639 \mathrm{e}+01$ & $2.000000 \mathrm{e}+00$ & $2.110000 \mathrm{e}+02$ \\
& & & \\
Second structural break & $7.728635 \mathrm{e}+00$ & $2.000000 \mathrm{e}+00$ & $3.090000 \mathrm{e}+02$
\end{tabular}

To the $95 \%$ confidence given $\mathrm{F}$ critical $=3.84$

\section{Annex 3: Correlations Table}

Table 8. Correlations table

\begin{tabular}{lccc}
\hline \hline Variable & $w$ & tot & $l p$ \\
\hline$w$ & 1 & $\mathbf{0 . 8 7 5}$ & $\mathbf{0 . 9 3 4}$ \\
tot & 0.875 & 1 & 0.906 \\
$l p$ & 0.934 & 0.906 & 1
\end{tabular}

$w$ corresponds to the real salary index, tot are the terms of exchange and $l p$ is the labor productivity. We can appreciate the high correlation present in the last two with the real salary, which is a basic requirement for them to be good instruments.

\section{Annex 4: Real Salary Index Regression}

Table 9. 2007.IV-2012.IV

\begin{tabular}{lcccc}
\hline \hline & Coefficient & Standard Error & Statistical-t & Prob \\
\hline $\mathrm{C}$ & 0.345 & 0.148 & 2.32 & 0.023 \\
tot & 0.618 & 0.164 & 3.77 & 0.000 \\
$\mathrm{lp}$ & 0.867 & 0.431 & 20.09 & 0.000 \\
\hline$R^{2}$ & 0.937 & & & \\
Adjusted $R^{2}$ & 0.935 & & & \\
Statistical F & 523.90 & & & \\
Prob (Statistical F) & 0.000 & & & \\
\end{tabular}

All variables are expressed as logarithms. $l p$ corresponds to the labor productivity

and tot are the terms of exchange.

\section{Annex 5: Wu-Hausman Test for Endogeneity 2SLS}

Table 10. Wu-Hausman test for endogeneity 2SLS

\begin{tabular}{lcc}
\hline \hline & Value & p-value \\
\hline Durbin $\left(\chi^{2}\right)$ & 10.511 & 0.0052 \\
Wu-Hausman (F) & 5.384 & 0.0069 \\
\end{tabular}

The null hypothesis is the exogeneity of the variables, which is rejected.

Therefore, it was correct to treat the endogeneity of the real salary and vacancies.

\section{Annex 6: Instrument Weakness Test}

Table 11. Wu-Hausman test for endogeneity 2SLS

\begin{tabular}{|c|c|c|c|c|c|}
\hline \multicolumn{6}{|c|}{ Statistical resume of the first stage of the regression } \\
\hline Variable & $R^{2}$ & Adjusted $R^{2}$ & Partial $R^{2}$ & $\mathrm{~F}(2,66)$ & Prob \\
\hline $\bar{w}$ & 0.969 & 0.966 & 0.154 & 5.937 & 0.004 \\
\hline$v$ & 0.601 & 0.564 & 0.148 & 5.682 & 0.005 \\
\hline \multicolumn{6}{|c|}{ Own minimum statistical value $=\mathbf{3 4 . 4 4 0}$} \\
\hline Critical value & $10 \%$ & $15 \%$ & $20 \%$ & $25 \%$ & \\
\hline 2SLS Wald test & 7.03 & 4.58 & 3.95 & 3.63 & \\
\hline
\end{tabular}

\section{Annex 7: White Noise Analysis}

\begin{tabular}{|c|c|c|c|c|c|c|c|c|}
\hline Autocorr & relation & Partial C & Correlatio & & $A C$ & PAC & Q-Stat & Prob \\
\hline 1 & ए & 1 & 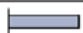 & 1 & 0.682 & 0.682 & 36.796 & 0.000 \\
\hline 1 & 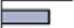 & 1 & 1 & 2 & 0.473 & 0.014 & 54.729 & 0.000 \\
\hline 1 & 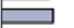 & 1 & $\square$ & 3 & 0.506 & 0.333 & 75.518 & 0.000 \\
\hline 1 & & 1 & $\square$ & 4 & 0.621 & 0.327 & 107.31 & 0.000 \\
\hline 1 & 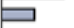 & ᄃ & 1 & 5 & 0.330 & -0.527 & 116.39 & 0.000 \\
\hline ' & פ & 1 & ' & 6 & 0.143 & -0.009 & 118.13 & 0.000 \\
\hline I & יפ - r l & I & b. & 7 & 0.184 & 0.058 & 121.05 & 0.000 \\
\hline 18 & 曰 & 1 & 曰, & 8 & 0.313 & 0.148 & 129.58 & 0.000 \\
\hline 10 & 31 & ᄃ & $=1$ & 9 & 0.068 & -0.232 & 129.99 & 0.000 \\
\hline 1 & 1 & I & 1 & 10 & -0.121 & -0.151 & 131.30 & 0.000 \\
\hline 10 & 1 & 17 & 1 & 11 & -0.091 & -0.041 & 132.05 & 0.000 \\
\hline 13 & b 1 & 1 & b & 12 & 0.041 & 0.067 & 132.20 & 0.000 \\
\hline 든 & 1 & $\square$ & $\exists 1$ & 13 & -0.198 & -0.234 & 135.90 & 0.000 \\
\hline$\theta$ & I & 1 & יק & 14 & -0.310 & 0.179 & 145.06 & 0.000 \\
\hline 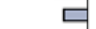 & ' & 1 & 51 & 15 & -0.242 & -0.087 & 150.77 & 0.000 \\
\hline 10 & I & 1 & I & 16 & -0.089 & 0.024 & 151.55 & 0.000 \\
\hline$\square$ & $\mathrm{I}$ & $\mathrm{I}$ & I & 17 & -0.254 & -0.021 & 158.06 & 0.000 \\
\hline$\square$ & I & 1 & I & 18 & -0.344 & -0.085 & 170.13 & 0.000 \\
\hline$\square$ & 1 & 1 & 1 & 19 & -0.289 & -0.078 & 178.81 & 0.000 \\
\hline 吅 & I & 1 & I & 20 & -0.145 & -0.014 & 181.03 & 0.000 \\
\hline$\square$ & I & 11 & 1 & 21 & -0.286 & -0.047 & 189.83 & 0.000 \\
\hline$\square$ & I & 1 & b & 22 & -0.331 & 0.109 & 201.84 & 0.000 \\
\hline 무요 & I & 1 & 1 & 23 & -0.240 & -0.041 & 208.27 & 0.000 \\
\hline 1 & ' & 15 & 1 & 24 & -0.093 & -0.063 & 209.26 & 0.000 \\
\hline 든 & 1 & 1 & b & 25 & -0.190 & 0.071 & 213.46 & 0.000 \\
\hline ㅁ & I & IL & 1 & 26 & -0.218 & -0.115 & 219.07 & 0.000 \\
\hline 1 & I & 1 & 1 1 & 27 & -0.139 & 0.062 & 221.40 & 0.000 \\
\hline 17 & I & 11 & 1 & 28 & -0.011 & -0.034 & 221,42 & 0.000 \\
\hline 10 & I & 10 & 1 & 29 & -0.118 & -0.098 & 223.19 & 0.000 \\
\hline ( & I & 1 & b. & 30 & -0.132 & 0.101 & 225.44 & 0.000 \\
\hline 11 & 1 & 1 & 曰 & 31 & -0.013 & 0.118 & 225.46 & 0.000 \\
\hline 1 & ים & ' & 51 & 32 & 0.144 & 0.043 & 228.26 & 0.000 \\
\hline
\end{tabular}

Figure 7. Regression Correlogram Vacancies-Unemployment

\begin{tabular}{|c|c|c|c|c|c|c|}
\hline Autocorrelation & Partial Correlation & & $A C$ & PAC & Q-Stat & Prob* \\
\hline ， 口 & I । & 1 & 0.098 & 0.098 & 0.6295 & 0.428 \\
\hline 단, & 단 & 2 & -0.120 & -0.130 & 1.5903 & 0.452 \\
\hline 1 & 1 & 3 & 0.065 & 0.094 & 1.8826 & 0.597 \\
\hline 1 & 1 & 4 & 0.135 & 0.105 & 3.1529 & 0.533 \\
\hline 1 & 1 & 5 & 0.007 & -0.000 & 3.1565 & 0.676 \\
\hline 1 & 1 & 6 & -0.004 & 0.020 & 3.1579 & 0.789 \\
\hline 10 & 10 & 7 & -0.076 & -0.099 & 3.5777 & 0.827 \\
\hline 1日 & 1日 & 8 & -0.154 & -0.156 & 5.3427 & 0.720 \\
\hline 17 & 17 & 9 & -0.051 & -0.044 & 5.5380 & 0.785 \\
\hline 101 & 101 & 10 & -0.077 & -0.103 & 5.9988 & 0.815 \\
\hline ו 1 & יاص 1 & 11 & 0.128 & 0.194 & 7.2854 & 0.776 \\
\hline 101 & 101 & 12 & -0.092 & -0.109 & 7.9689 & 0.788 \\
\hline 1 口 & 17 & 13 & -0.125 & -0.039 & 9.2429 & 0.754 \\
\hline 171 & $1 \mathrm{~b}$ & 14 & 0.067 & 0.065 & 9.6138 & 0.790 \\
\hline 101 & '드 ' & 15 & -0.084 & -0.204 & 10.209 & 0.806 \\
\hline 1드 & 10 & 16 & -0.169 & -0.125 & 12.712 & 0.694 \\
\hline 10 & 10 & 17 & -0.079 & -0.115 & 13.262 & 0.718 \\
\hline 101 & 1 & 18 & 0.046 & 0.024 & 13.458 & 0.764 \\
\hline $1[1$ & 1 & 19 & -0.069 & -0.001 & 13.899 & 0.790 \\
\hline ום & $1 \square$ & 20 & 0.157 & 0.223 & 16.246 & 0.701 \\
\hline '단 & 뭉 & 21 & -0.167 & -0.230 & 18.951 & 0.588 \\
\hline 11 & 11 & 22 & -0.025 & 0.024 & 19.012 & 0.645 \\
\hline 1 & 11 & 23 & 0.101 & -0.042 & 20.065 & 0.638 \\
\hline 161 & 10 & 24 & 0.049 & -0.050 & 20.319 & 0.678 \\
\hline 161 & $1]$ & 25 & 0.044 & 0.038 & 20.524 & 0.719 \\
\hline 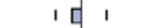 & 10 & 26 & -0.095 & -0.132 & 21.521 & 0.715 \\
\hline 12 & 17 & 27 & -0.063 & 0.019 & 21.974 & 0.739 \\
\hline 10 & $1 \mathrm{C}$ & 28 & -0.079 & -0.136 & 22.706 & 0.748 \\
\hline
\end{tabular}

Figure 8. Correlogram 2SLS 


\section{Annex 8: Graphical Evolution of Data Series}
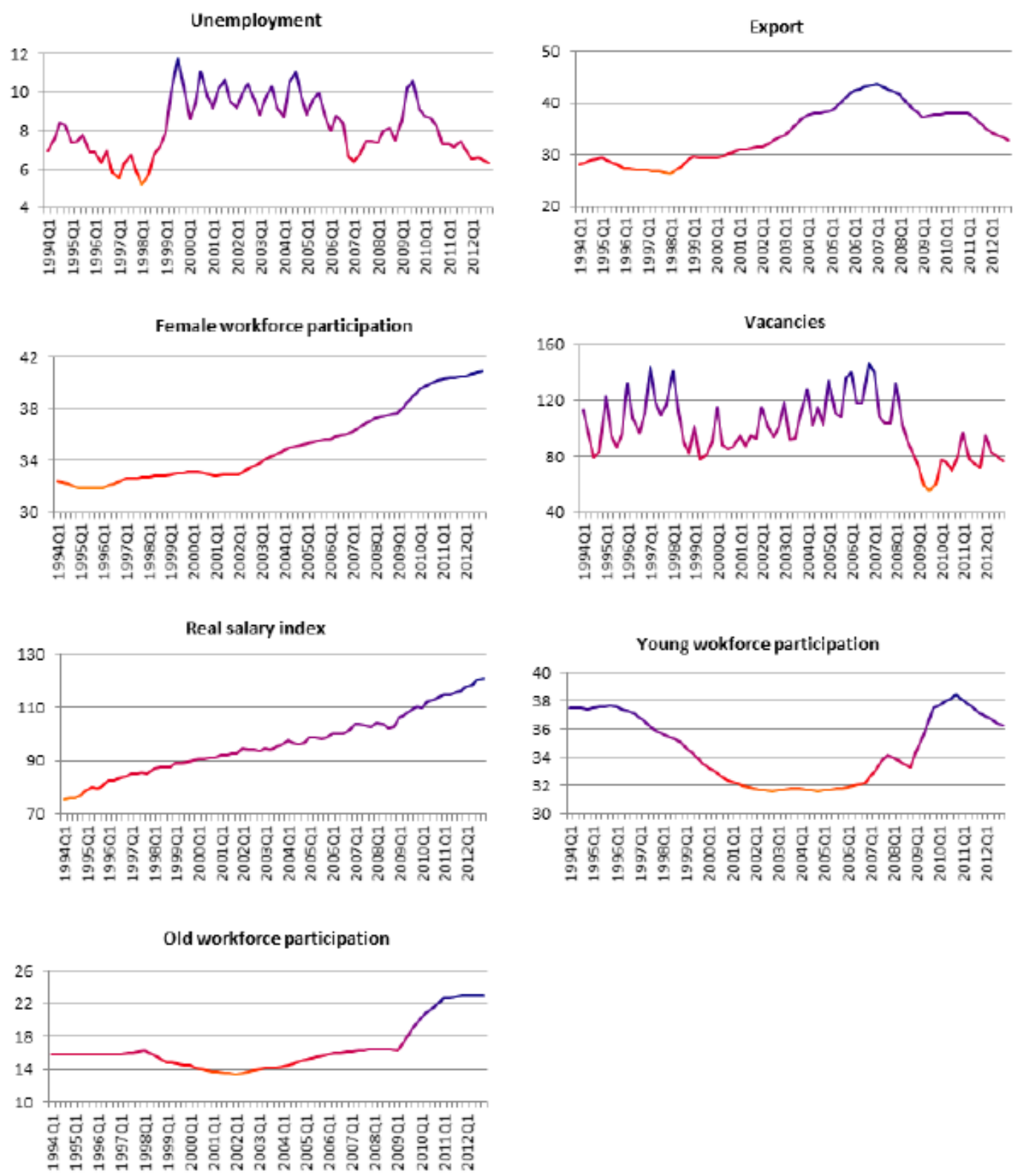

Figure 9. Graphical Evolution of Data Series

\section{REFERENCES}

[1] Barnichon, R. and Figura, A. (2011). What Drives Matching Efficiency? A Tale of Composition and Dispersion.

[2] Benito, A. (2009). How Policy Affects Labor Demand and Labor Productivity? IZA World of Labor 2017:340

[3] Bellani, D., García, P. and Pastén, E. (2002). Curva de Beveridge, Vacantes y Desempleo: Chile 1986-2002.II. Revista Economía Chilena, Vol. 5(3):105-119

[4] Beveridge, W. H. (1944). Full Employment in a Free Society. Allen and Unwin, London.

[5] Blanchard, O.J. and Diamond, P. (1989). The Beveridge Curve. Brooking Papers on Economic Activity, No 1, 1-76

[6] Bleakley, H. and Fuhrer, J. (1997). Shifts in the Beveridge Curve, Job Matching, and Labor Market Dynamics. New England Economic Review, Sept: 3-19.

[7] Bonthuis, B., Jarvis, V. and Vanhala, J. (2015). Shifts in the Euro Area Beveridge Curves and Their Determinants. IZA Journal of Labor Policy, 5(1):20.

[8] Bonthuis, B., Jarvis, V. and Vanhala, J. (2013). What's Going on Behind the Euro Area Beveridge Curve(s)? ECB Working Paper, September 2013.

[9] Borchert, I. and Mattoo, A. (2009). The Crisis' Resilience of Services Trade. Policy Research Working Paper Series, No. 4917, The World Bank. 
[10] Borsch-Supan, A.H. (1991). Panel Data Analysis of the Beveridge Curve: Is There a Macroeconomic Relation Between the Rate of Unemployment and the Vacancy Rate? Economica 58: 279-297.

[11] Bouvet, F. (2009). The Beveridge Curve in Europe: New Evidence Using National and Regional Data. The EUSA 11th Biennial International Conference, p. 23-5.

[12] Bova, E., Jalles, J.T. and Kolerus, C. (2016). Shifting the Beveridge Curve: What Affects Labor Market Matching? IMF Working Paper.

[13] Corbo, V. and Schmidt-Hebbel, K. (2011). The International Crisis and Latin America: Growth Effects and Developments Strategies. The World Bank.

[14] De Francesco, A.J. (1999). The Relationship between Unemployment and Vacancies in Australia. Applied Economics, 31, 641-652.

[15] Diamond, P. and Sahin, A. (2014). Shifts in the Beveridge Curve. Federal Reserve Bank of New York, Staff Reports n. 687.

[16] Gamberoni, E., Von Uexkull, E. and Weber, S. (2010). The Role of Openness and Labor Market Institutions for Employment Dynamics during Economic Crises. Employment Working Papers, No. 2010-68, International Labor Office.

[17] Groenewold, N. (2003). Long-Run Shifts of the Beveridge Curve and the Frictional Unemployment Rate in Australia. Australian Journal of Labor Economics, Vol. 6, No.1, p. $65-82$.

[18] Hausman, J. (1978). Specification Tests in Econometrics. Econometrica, 46:1251-1271.

[19] Hobijn, J. and Sahin, A. (2013). Beveridge Curve Shifts across Countries Since the Great Recession. Federal Reserve Bank of San Francisco.
[20] Mehrotra, N. and Sergeyev, D. (2012). Sectoral Shocks, the Beveridge Curve and Monetary Policy. Mimeo, Columbia University.

[21] Kugler, A. (2014). Labor Market Analysis and Labor Policymaking in the Nation's Capital. Industrial and Labor Relations Review, 67:594.

[22] Mujica, R. (2007). Descripción Crítica de los Fundamentos de la Curva de Beveridge y de su Uso como Herramienta de Análisis del Mercado Laboral. Tesis de Magíster, PUC.

[23] Petrongolo, B. and Pissarides, C. (2001). Looking Into the Black Box: A Survey of the Matching Function. Journal of Economic Literature, 39, 390-431.

[24] Pissarides, C. (2000). Search Employment With On-the Job Search. Second Edition. Review of Economic Studies. Vol. 46, n. 4 .

[25] Saglam, B. and Gunalp, B. (2012). The Beveridge Curve and Labor Markets Dynamics in Turkey. Applied Economics, 44:24.

[26] Sell, F. and Reinisch, D. (2013). How Do Beveridge and Phillips Curves in the Euro Area Behave Under the Stress of the World Economic Crisis? University of Munich.

[27] Stock, J. and Yogo, M. (2002). Testing for Weak Instruments in Linear IV Regressions. NBER Technical Papers 284.

[28] Valletta, R. (2005). Why Has the Beveridge Curve Shifted Back? New Evidence Using Regional Data. FRB SF Working Paper 2005-25.

[29] Wall, H.J. and Zoega, G. (2002). The British Beveridge Curve: A Tale of Ten Regions. Oxford Bulletin of Economics and Statistics, 64 (3), 257-276.

[30] Wu, M.D. (1973). Alternative Tests of Independence between Stochastic Regressors and Disturbances Stochastic Regressors and Disturbances. Econometrica, 40:733-750. 